\title{
Las mujeres escriben sobre la Resistencia francesa
}

\author{
Brigitte LEGUEN \\ Departamento de Filología Francesa \\ Universidad Nacional de Educación a Distancia \\ bleguen@flog.uned.es
}

\begin{abstract}
RESUMEN
Durante la Segunda Guerra Mundial, la Resistencia interior francesa hizo necesaria la participación de todas las fuerzas civiles de la población francesa. La participación de las mujeres y su valor en la lucha contra la Ocupación quedaron reflejados en gran número de relatos testimoniales escritos por ellas; aquel escenario se trasladó también a la ficción literaria contribuyendo a mantener viva la memoria de aquellos años de contienda y de cuestionamiento de la identidad política y cultural de los pueblos europeos.
\end{abstract}

Palabras clave: mujer y escritura, memoria, Historia, relatos de vida, ficción, autoficción.

\section{Women write about the French Resistance}

\begin{abstract}
During WWII, the French interior resistance called for the participation of all the civilian forces within the country's population. The participation of women and their bravery in the fight against occupation were reflected on the great number of written witness accounts produced by them which were also passed on to literary fiction, thus contributing to keeping alive the memory of those years of struggle and questioning of the political and cultural identity of the European peoples.
\end{abstract}

Keywords: women and writing, memory, History, life stories, fiction, autofiction.

Dada la amplitud del tema y el abundante corpus de relatos unidos a la experiencia de la Resistencia interior en Francia durante la Segunda Guerra Mundial, hemos optado por apoyar nuestro análisis en una serie de relatos inspirados en las experiencias vividas durante aquel período. Algunos son relatos de vida que recogen de forma testimonial los acontecimientos del período. Otros introducen en la ficción el escenario histórico de la Resistencia y lo convierten en el marco de la acción. Todos los textos a los que nos referimos están escritos por mujeres.

El papel relevante del eje histórico en este tipo de escritura nos invita a abordar y evocar en una primera etapa el contexto de los hechos a grandes rasgos. Nos 
situamos en los años de la Segunda Guerra Mundial (1940-1945) en la Francia ocupada por los alemanes y dividida entre una Francia que se somete a la política del mariscal Pétain, aliado con los alemanes, y otra que busca su liberación respondiendo al llamamiento del General de Gaulle en Londres al cabo de varios años de Ocupación.

Obviamente, esta situación es muy compleja y a menudo percibida como confusa por parte del propio pueblo francés.

Mucho más clara resultará ser la actitud de Alemania ante la invasión de Europa. Recordemos que la ambición de Hitler es formar en torno al gran Reich germánico una Europa endeudada y obligada a poner sus reservas económicas y humanas al servicio del gran Reich.

Bien es verdad también que dentro de la propia Alemania existirán grupos que se opondrán al nazismo y a su ideología imperialista.

Esta «nazificación» de Europa se enfrenta muy pronto a movimientos de resistencia que poco a poco se organizan en redes de resistentes a medida que se endurece el proceso de ocupación y de detenciones no solamente de ciudadanos judíos sino de cualquier otro que pretenda sublevarse contra las medidas del tercer Reich.

La Resistencia, dadas las condiciones de ocupación y de colaboración (no hay que olvidar que en el seno de la sociedad francesa, muchos apoyan y justifican lo que consideran como la gran oportunidad de la nueva Europa, lo que significa que tenemos a «dos Francias» enfrentadas y enemigas dentro del mismo país).

La Resistencia tanto militar como civil se va adaptando a las circunstancias adversas y organiza sus redes en todo el territorio nacional haciendo suyo el lema «Obedecer es traicionar, desobedecer es servir».

Esta Resistencia desarrolla también una importante labor de propaganda a través de la prensa clandestina (como por ejemplo Libération, periódico en el que colaboró activamente la resistente Lucie Aubrac sobre la que volveremos más adelante) y a través de la difusión de folletos repartidos por todo el país.

El lugar de las mujeres en esta contienda es complejo: ellas representan lo que Catherine Varlin denomina como «la ville engloutie» (Varlin 1985: 101-103), en otras palabras, un colectivo doblemente clandestino por su condición de mujer y por su actividad subversiva. Recordemos que todavía las mujeres francesas no tienen derecho al voto (empiezan a votar en 1944 al final de la guerra gracias al apoyo del general de Gaulle) y no son, por tanto, todavía ciudadanas de pleno derecho.

Por otra parte, su educación no les prepara a las condiciones adversas a las que se exponen los combatientes-hombres. Por ello el reclutamiento se hizo al principio mayoritariamente entre determinados sectores más preparados y aguerridos: Refugiadas de los países del Este fruto de la inmigración provocada por la represión tzarista, otras huidas de los países ocupados por la Alemania hitleriana, jóvenes militantes comunistas o procedentes de organizaciones protestantes y sionistas (organizaciones ya comprometidas antes de la guerra), refugiadas de la Italia fascista y de la España franquista... En general se puede afirmar que sin ser un vínculo natural y siempre fácil de valorar, el compromiso de las minorías para la defensa de los dere- 
chos del hombre y de la libertad reaparece cíclicamente como una constante de la Historia del mundo. Pero también se incorporaron a estos grupos más adiestrados muchas espontáneas que tuvieron un papel de gran relevancia sin tener una preparación previa.

A pesar de estas circunstancias nada favorables a su integración al conflicto bélico, consiguen participar de un modo muy activo, tanto desde la vida civil ordinaria haciéndose con todas las formas de resistencia civil, como dentro de los maquis manejando explosivos y asaltando puntos estratégicos controlados por los alemanes.

Al final de la guerra están poco reconocidas y sub-representadas. Esta cuestión está ya muy estudiada y se sabe que el reconocimiento oficial en el marco de las ceremonias conmemorativas y la entrega de condecoraciones representan un $10 \%$ de la participación femenina consignada (Jauneau 2008).

Este «olvido» entre comillas en la historiografía de la Resistencia (Thalmann 1995) está relacionado con una visión sexuada de dicha participación y habrá que esperar en muchos casos los movimientos del 68 y los cambios que acarrearon para ver la publicación de muchos relatos testimoniales: por otra parte, el acontecer de la «Nueva Historia» ayudó a rescatar del olvido aspectos que la ciencia histórica había considerado como menores y subalternos anteriormente. (No olvidemos que l'Histoire des femmes en Occident, de Michelle Perrot y Georges Duby, solo se empieza a publicar por tomos a partir del año 1990 en Francia) ${ }^{1}$.

No debemos obviar además que la Resistencia es circunstancial y relacional. Existe en función de una situación de ocupación y se define en relación a un contexto determinado. Su carácter puntual y circunstancial le somete a una transmisión más frágil. Además, las representaciones que habitan la memoria de este acontecimiento siguen siendo largo tiempo y principalmente un asunto de los hombres que siguen siendo en el contexto social de la época, los actores mayoritarios del conflicto y los que controlan más el espacio público.

La novela Le silence de la mer de Vercors (1942), películas como las de Max Ophüls, Le chagrin et la pitié (1971) o la de Claude Chabrol Une affaire de femme (1988) son obras en las que las mujeres ocupan un lugar de mera figuración y son una señal de la poca importancia que se da a las acciones generadas por este colectivo.

Los únicos estudios desde el «Gender» como vector de análisis se deben a estudiosas norteamericanas como Joan Wallach Scott, o Paula Schwartz mientras que la investigación en Francia es más tardía y se inicia sobre todo a partir de los años 90 (Laurent Douzou, Claire Andrieu, Sylvie Chaperon, Evelyne Morin-Rotureau, etc...).

Los textos relacionados con el tema de la Resistencia son de diversas índoles y varían según el momento cronológico y la procedencia.

Tenemos esencialmente dos tipos de textos: los de ficción que incorporan en su argumento elementos de la Historia, momentos fuertes y traumáticos y otros basados en hechos reales y en testimonios y vivencias. Tanto unos como otros respon-

${ }^{1}$ Debemos los primeros estudios sobre esta perspectiva a las norteamericanas como Paula Schwartz. 
den a un intento de lo que T. Todorov define como «relato ejemplar» en el que la veracidad de unos acontecimientos está desvelada gracias al relato 2 .

No entraremos en debatir sobre aspectos críticos pero que quede consignado el interés del acercamiento crítico de Todorov, el de Paul Ricoeur quien asocia Histoire et vérité, y el conocidísimo texto de Genette Fiction et diction sin olvidar los valiosísimos trabajos de Hayden White sobre la inserción de la Historia en la Ficción.

Después de diversas etapas en el ámbito de la crítica en las que se debatía sobre el significado de la ficción y de la dicción, estamos en el momento presente ante lo que la crítica francesa denomina como nonfiction, un género que vuelve a remover otras incertidumbres. Tal y como lo expresa el escritor J.G. Ballard, «nous vivons à l'intérieur d'un énorme roman. Il devient de moins en moins nécessaire pour l'écrivain de donner un contenu fictif à son œuvre. La fiction est déjà là. Le travail du romancier est d'inventer la réalité» ${ }^{3}$.

En este contexto ya delimitado abordaremos una serie de relatos vinculados al recuerdo de la Resistencia: relatos de vida y relatos de ficción. Existen relatos testimoniales de la «primera hora» escritos en caliente por deportadas que se salvaron, como en el caso del diario de Marcelle Gougat autora de un texto escrito durante su estancia en Ravensbrück y cuidadosamente conservado hasta su publicación después de la guerra. Otra, como Violette Lecoq ofreció un testimonio en forma de dibujos hechos en su encarcelamiento también en Ravensbrück que sirvió luego de prueba testimonial en los procesos posteriores.

Pero hemos de destacar que la gran mayoría de los relatos surgen a finales de los años sesenta y después de los acontecimientos que marcan un gran cambio en la toma de consciencia de las mujeres frente a su identidad personal y social. En un momento en el que impera el lema acuñado por Michel Foucault según lo cual «lo personal es político», dos generaciones de mujeres toman la palabra: por una parte, están las resistentes que han vivido la Segunda Guerra Mundial como adultas comprometidas y por otra las llamadas «hijas de la Ocupación» que vivieron la guerra durante su infancia o en su primera adolescencia y que intentan aclarar cómo fue su vida en esos años oscuros de la Ocupación.

Los escritos de las resistentes son también (y por desgracia) a menudo una respuesta al negacionismo ${ }^{4}$ imperante. En esta misma línea asistimos a una ola de publicaciones de autobiografías en respuesta al proceso de Klaus Barbie (en 1987).

${ }^{2}$ Este proceso de desvelamiento aparece ya en su obra La découverte de l'Amérique en 1982 y sigue con Un homme dépaysé o Une tragédie française, en el que Todorov escenifica los últimos enfrentamientos entre los franceses de las dos orillas poniendo de manifiesto las características de la guerra civil y su desenlace dentro de las fronteras francesas.

3 Prólogo a la reedición de 1995 de la novela Crash. Por otra parte, las escrituras de vidas se imponen cada vez más en el paisaje literario contemporáneo. Véase Solange Gil, «El fenómeno de las escrituras de vida en la narrativa francesa del «Extremo contemporáneo», Thélème, vol. 29, n 1 (2014), pp. $55-73$.

${ }^{4}$ Es la distorsión ilegítima del registro histórico de tal manera que ciertos eventos aparezcan de forma más favorable o desfavorable, mientras que el revisionismo histórico se ocupa de la corrección legítima del conocimiento existente sobre un evento histórico. 
Citemos Le Sel de la mine de Raymonde Guyon-Belot, Ils partiront dans l'ivresse de Lucie Aubrac, el testimonio de Cécile Ouzoulias Romagon J'étais agent de liaison des FTPF, todos ellos textos que intentan transmitir la realidad de los hechos tal y como acontecieron con toda la fuerza de la proximidad en el ejercicio de la memoria.

El caso de Edith Thomas es algo diferente. Nacida en 1909 forma parte de las resistentes intelectuales comprometidas. Se adhiere al partido comunista en 1942 y publica bajo el seudónimo de Jean Le Guern.

Sus tardías memorias tituladas Le Témoin compromis, publicadas en 1995 aunque redactadas en 1952, y Pages de journal son un testimonio de la resistencia intelectual durante la Ocupación. Estos textos, además de ser un excelente testimonio, tienen una gran calidad literaria debido a la doble condición de escritora y resistente de Thomas.

La siguiente generación está más marcada por la perspectiva feminista de los años setenta y por la necesidad de solucionar el trauma sufrido durante la niñez o la adolescencia. Alguna, como Evelyne le Garrec, plantea su relato como un «autoreportaje» según sus propias palabras, en el que describe el colaboracionismo de su padre y el drama que vivió en su infancia mezclando enfoques autobiográficos con datos históricos. Su libro La Rive allemande de ma mémoire (publicado en 1980) es un modelo a menudo retomado en el que los sentimientos de culpabilidad van unidos al relato del exterminio.

En estos relatos, la Ocupación es un escenario variable según la edad de las protagonistas. Las que vivieron la guerra en su edad adulta encontraron en la lucha en la clandestinidad un camino para medir sus fuerzas y abrir la vía de la emancipación a la que no se les había preparado explícitamente.

Las hijas de la Ocupación, más jóvenes, educadas en el pensamiento de los años 70 , son mucho más críticas por lo general y denuncian los prejuicios sexistas que sostenían la ideología de la Colaboración.

Son muchos los relatos de calidad y nos limitaremos a nombrar los más relevantes y los que dejaron mayor huella en la memoria colectiva, empezando por el de Lucie Aubrac: su historia es ejemplar y en algunos momentos rocambolesca. Esta militante de las juventudes comunistas antes de la guerra se casa con el también resistente Raymond Samuel y organiza en agosto de 1940 la huida de su marido prisionero de guerra en el campo de Sarrebourg y se adhiere a la red de resistencia liderada por d'Astier de la Vigerie, un conocido periodista. Su historia es una larga sucesión de acontecimientos impactantes que cuenta en Ils partiront dans l'ivresse, un relato autobiográfico adaptado al cine a finales de los noventa en Francia.

Pero sin duda lo que más conocemos sobre aquel período se lo debemos a la ficción literaria y a los diarios e intercambios epistolares.

La guerra, la Resistencia y la colaboración entran como marco predilecto de la ficción escrita por mujeres que conocieron, de cerca o de más lejos, la experiencia de la guerra y de la clandestinidad.

En el campo literario francés y francófono existen grandes escritoras que nos ofrecen su visión personal del conflicto y de las tensiones generadas por la situación bélica. 
Recordemos el Journal de guerre de Simone de Beauvoir que podemos poner en relación con la correspondencia entre Sartre y Beauvoir en la misma época, en el que analiza detalladamente todas las circunstancias de la vida en medio de la contienda. El conocidísimo texto de Marguerite Duras La douleur es otro gran texto en el que la novelista evoca la vuelta de su marido Robert Antelme (autor también de un único libro testimonial titulado La especie humana que ha sido reeditado hace unos años) y en el que plantea una serie de opiniones muy ambiguas sobre los crímenes de guerra y los agentes de la ocupación.

Citemos también la magnífica trilogía de la escritora Charlotte Delbo Auschwitz et après. La autora se unió junto a su marido a la importante red de resistencia Georges Politzer y sobrevivió a su paso por Auschwitz en uno de los pocos transportes no judíos para este destino. Como Edith Thomas y otras, retuvo la publicación de su obra hasta el año $1965^{5}$.

Menos violentos y trágicos son los textos de la escritora Clara Malraux (primera mujer del escritor André Malraux) que ofrece una visión más cotidiana y tradicional de la guerra y de la participación de las mujeres lejos del frente.

Todos estos textos tienen en común un trabajo de desvelamiento del conflicto y de sus efectos; casi siempre se emplea una instancia narrativa en primera persona convirtiendo cada relato en un relato ejemplar siguiendo la formulación de Todorov.

Después de este breve repaso conviene subrayar el impacto que ha tenido y que tiene todavía esta etapa en la memoria de los franceses y en sus literaturas tanto documental como ficcional ${ }^{6}$.

La participación de las mujeres en esta etapa de la Historia de Francia y sus relatos posteriores ha hecho posible su mayor presencia testimonial y ha dado lugar a obras de calidad que no han recibido todavía toda la atención que se merecen.

Tanto en los relatos sobre hechos auténticos y vivencias asociadas a un contexto real e histórico como en las historias en las que la ficción enlaza con la Historia, la búsqueda de estos relatos confluye en la búsqueda de una voz en la que el destino individual (en este caso específico, el de las mujeres) enlaza con la memoria de un destino colectivo compartido.

Sin embargo esta presencia sigue siendo muy dispersa y mal archivada tanto en el dominio de la historiografía como en el de la historia literaria que queda todavía por hacer (Touret 2010).

5 Le Convoi du 24 janvier, Les Éditions de Minuit, 1965, 1978, 1995.

Auschwitz et après, 3 tomes: Aucun de nous ne reviendra, Éditions Gonthier SA Genève. Collection Femmes, publiée sous la direction de Colette Audry, 1965. Aucun de nous ne reviendra, Réédition: Les Éditions de Minuit, 1970, 1979, 1995.Une connaissance inutile, Les Éditions de Minuit, 1970. Mesure de nos jours, Les Éditions de Minuit, 1971, 1994.

${ }^{6}$ Además de los textos escritos se han hecho numerosos documentales y películas cuyas protagonistas son mujeres miembros de la resistencia. 


\section{Referencias bibliográficas:}

AUBRAC, Lucie (1984): Ils partiront dans l'ivresse. Paris: Seuil.

BALLARD, James Graham (1979): Crash. Barcelona: Minotauro.

BEAUVOIR (de), Simone (1990): Journal de guerre. Paris: Gallimard.

DELBO, Charlotte (1965): Auschwitz et après: aucun de nous ne reviendra. Paris: Éditions de Minuit.

- (1970): Une connaissance inutile. Paris: Éditions de Minuit.

- (1971): Mesure de nos jours. Paris: Éditions de Minuit.

Duby, George, y PERrot, Michelle (dirs.) (1990): Histoire des femmes en Occident. Paris: Plon.

DURAS, Marguerite (1985): La douleur. Paris: P.O.L.

GenetTe, Gérard (1991): Fiction et diction. Paris: Seuil.

GIL, Solange (2014): «El fenómeno de las escrituras de vida en la narrativa francesa del «Extremo contemporáneo»»». Thélème 29/1: 55-73.

GoUgAT, Marcelle [archivo]: Archives de la bibliothèque de documentation internationale, dossier 77.

GuYON-Belot, Raymonde (1990): Le sel de la mine. Paris: Édition France-Empire.

JAUNEAU, Élodie (2008): «Des femmes dans la France combattante pendant la Deuxième Guerre mondiale: Le Corps des Volontaires françaises et le Groupe Rochambeau» [en línea]. Genre \& Histoire 3/Automne 2008: Les médiévistes et l'histoire du genre en Europe. En : http://genrehistoire.revues.org/373 [Consulta: 13/05/2016].

LE GARREC, Évelyne (1980): La rive allemande de ma mémoire. Paris: Seuil.

LECOQ, Violette (1982): Ravensbrück, 36 dessins à la plume. Coll. Musée de la Résistance nationale.

MALRAUX, Clara (1947): La maison ne fait pas crédit. Paris: Grasset.

OuZOUlias-Romagon, Cécile (1988): J'étais agent de liaison des FTPF. Paris: Éditions Messidor.

Ricoeur, Paul (2001): Histoire et vérité. Paris: Seuil.

ThalmanN, Rita (1995): «L'oubli des femmes dans l'historiographie de la Résistance» [en línea]. Clio. Femmes, Genre, Histoire 1/1995: Résistances et libérations. France 19401945. En: http://clio.revues.org/513 [Consulta: 13/05/2016].

ThomAs, Edith (1995a): Le témoin compromis. Paris: Éditions Viviane Hamy.

- (1995b): Pages de journal 1939-1944. Paris: Éditions Viviane Hamy.

TODOROV, Tzvetan (1982): La conquête de l'Amérique. La question de l'Autre. Paris: Seuil.

- (1998): L’homme dépaysé. Paris: Seuil.

- (2004): Une tragédie française. Paris: Seuil.

TOURET, Michèle (2010): «Où sont-elles ? Que font-elles ? La place des femmes dans 1'histoire littéraire. Un point de vue de vingtiémiste [en línea]». Fabula-LhT 7/abril 2010: Y a-t-il une histoire littéraire des femmes ? En: http://www.fabula.org/lht/7/touret.html [Consulta: 13/05/2016].

VARLIN, Catherine (1985): «Une ville engloutie: la résistance des femmes juives», en Les juifs dans la résistance et la libération, Rhicoj (ed.), pp. 101-103. Paris: Éditions du Scribe.

WHITE, Hayden (2003): El texto histórico como artefacto literario y otros escritos. Barcelona, Buenos aires, México: Editorial Paidós.

- (2010): Ficción histórica, historia ficcional y realidad histórica. Buenos Aires: Prometeo Libros. 